\title{
Hacia una didáctica artística decolonial. Una propuesta de aula intercultural desde el pueblo Misak $^{1}$
}

\author{
Towards an artistic decolonial didactics. A proposal in the intercultural \\ classroom from the Misak community
}
Rumo a uma Didática Artística Decolonial. Uma proposta de aula intercultural a partir do povo Misak

Recepción: 09/09/2019

Evaluación: 18/02/2020

Aceptación: 01/04/2020

Artículo de Investigación - Reflexión

https://doi.org/10.19053/01227238.10903

José Ignacio Bolaños Motta ${ }^{2}$

https://orcid.org/0000-0002-9976-18082

Universidad de los Llanos, Colombia

José Felipe Tumiñá ${ }^{3}$

Clementina Ullune Almendra ${ }^{4}$

Institución Educativa La Campana - Guambía, Colombia

\section{RESUMEN}

Objetivo: La presente investigación pretendió generar un fortalecimiento de las prácticas artísticas tradicionales Misak, a través de una propuesta didáctica basada en las denominadas pedagogías decoloniales, como propuesta intercultural. El estudio se realizó con veinticinco escolares de los grados segundo y tercero del centro docente La Campana, institu- ción ubicada en el municipio de Guambía (Cauca) en Colombia. Metodo: El modelo de investigación se desarrolló a través de un estudio de tipo cualitativo y desde la perspectiva de la investigación-acción. Las estrategias desarrolladas para la recolección de la información fueron: análisis de los Diarios de Campo producto de las actividades, y las entrevistas realizadas a

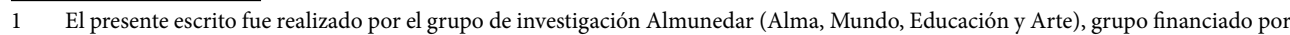
la Universidad de los Llanos desde 2017.

2 Magíster en Educación de la Universidad del Cauca, se desempeña como docente e investigador en la Universidad de los Llanos en Villavicencio (Meta). Es coordinador del grupo de investigación Almunedar de la misma Universidad. Correo electrónico: jbolanos@unillanos.edu.co,

3 Licenciado en Educación Básica con énfasis en educación artística, es docente en la Institución Educativa La Campana en el área de educación artística. Realiza diversos liderazgos en el campo de la educación artística dentro de su resguardo indígena. Es bajista de la agrupación de música andina Piurek. Correo electrónico: jtumina@unicauca.edu.co

4 Licenciada en Educación Básica con énfasis en Educación Artística. Es docente en la Institución Educativa La Campana. Desde el año 2018 ejerce el cargo de secretaria zonal del cabildo indígena. Correo electrónico:clementkarita@gmail.com 
diversos sectores de la comunidad escolar. Originalidad: El estudio busca evidenciar la posibilidad de desarrollar una didáctica artística decolonial, en contribución a que los pueblos del mundo desarrollen sus propios modelos educativos y desde sus propias perspectivas disciplinares. Conclusiones: Los resultados evidencian la evolución que se ha hecho posible al interior de los contextos indígenas, indicándose en este proceso un grupo de esfuerzos en lo que respecta al planteamiento del cómo, el qué, la cultura y la necesidad de sistematizar el saber didáctico en el campo de la educación artística. Palabras clave: didáctica, decolonialidad, educación artística.
The current study was developed with 25 students from $2^{\text {nd }}$ and $3^{\text {rd }}$ grade of La Campana school, this institution is in the town of Guambia (Cauca). The main objective was to generate a strengthening of the traditional artistic practices of the Misak indigenous population through a didactic proposal that starts from the ideals of the so-named Decolonial Pedagogies from an intercultural didactic model. In terms of the methodology, a qualitative study was carried out, from the action research perspective. The techniques developed to collect the information were analysis of the Journals that views carried out in different sectors in charge of the school The results evidenced that the artistic themes considering the own and intercultural tradition conceived an approach and appreciation for the own culture, because it is necessary to generate new educational practices and Decolonial Didactic strategies, which strengthen the know-how of the Educational Institution and, at the at the same time, traditional knowledge.

Keywords: Didactics; decoloniality; artistic education.

\section{RESUMO}

O presente estudo foi realizado com 25 estudantes, dos Segundo e Terceiro anos, do Centro Docente La Campana, instituição localizada no município de Guambía (Cauca); com o objetivo principal de gerar um fortalecimento das práticas artísticas tradicionais da população indígena Misak, por meio de uma proposta didática que parte dos ideais das denominadas Pedagogias Decoloniais, a partir de um modelo didático intercultural. Em termos de metodologia se desenvolveu um estudo de tipo qualitativo, desde a perspectiva da Pesquisa-Ação. As técnicas desenvolvidas para a coleta dos dados foram: análise dos Diários de Campo que emergiram das atividades e entrevistas a diversos setores encarregados pela escola. Os resultados evidenciaram que as temáticas artísticas em relação com a própria tradição e em perspectiva intercultural geraram aproximação e valorização da cultura própria, porquanto se faz necessário gerar novas práticas educacionais e estratégias Didáticas Decoloniais que fortaleçam o saber da Instituição Educativa e, ao mesmo tempo, o saber tradicional.

Palavras-chave: didática; decolonialidade; educação artística. 


\title{
INTRODUCCIÓN
}

\author{
"Ciertas cosas pueden capturar tu mirada, \\ sigue solo a las que puedan capturar tu corazón". \\ Proverbio Sioux
}

La presente investigación se llevó a cabo en la Institución Educativa La Campana, conformada en su mayoría por población indígena Misak, procedente en general, del resguardo de Guambía ${ }^{5}$, ubicado en el departamento del Cauca (Colombia). El proyecto contó con una población estudiantil de veinticinco escolares, de los cuales diecisiete pertenecían al grado segundo, y ocho estudiantes al grado tercero, todos pertenecientes al ciclo colombiano de Educación Básica Primaria. El problema de investigación afrontado en el contexto estuvo relacionado con la denominada "aculturación o transculturación" 6 de la "identidad étnica" ${ }^{7}$, entendiendo que la aculturación hace referencia al proceso de inestabilidad o a "un fenómeno en perpetuo movimiento, que por ende desafía cualquier definición rígida" 8 , o como "el proceso de tránsito de una cultura a otra y sus repercusiones sociales" ${ }^{\prime \prime}$, procesos que pueden presentarse bien sea en una escuela mestiza que recibe población indígena, o en una "escuela indígena"10 que cuenta con población mestiza. En términos generales, podría decirse que la aculturación hace referencia al proceso a través del cual una cultura se mueve hacia otra u otras culturas, fenómeno que, en términos del presente estudio, se presentaba de manera muy puntual en la juventud indígena y en lo referente a las "artes del espectáculo"11, o expresiones artísticas no indígenas, pero que se practicaban en una escuela de currículo propio ${ }^{12}$. Dicho lo anterior en otras palabras: formación dentro de la cultura y para la cultura, haciéndose referencia en este caso a la cultura Misak. Muchos de los escolares pertenecientes no solo a los cursos mencionados sino también a la Institución Educativa en los grados de primaria y bachillerato, habían desarrollado una tensión con su identidad Misak y la cultura popular que les correspondía observar en los medios de comunicación y, aunque se diría que las "construcciones identitarias necesitan ser pensadas desde una perspectiva que reconozca el desacuerdo, las tensiones

5 Guambía es llamada Silvia por el mundo mestizo, nombre que no goza de reconocimiento entre las poblaciones con las cuales se desarrolló esta propuesta.

6 Héctor Pérez-Brignoli, "Aculturación, transculturación, mestizaje: metáforas y espejos en la historiografía latinoamericana", Cuadernos de Literatura vol. XXI, n. ${ }^{\circ} 41$ (2017): 101.

7 Miguel Sámano, "Identidad étnica y la relación de los pueblos indígenas con el Estado mexicano", Ra Ximhai vol. 1, n. ${ }^{\circ} 2$ (2005): 240.

8 Pérez-Brignoli, "Aculturación, transculturación, mestizaje”.

9 Carlos Chiappe, “¿Transculturación o acultura? Matices conceptuales en Juan van Kessel y Alejandro Lipschutz”, Revista de Ciencias Sociales n. $^{\circ} 35$ (2015): 52.

10 Ramón Hernández, "Identidad cultural o aculturación: el dilema de una escuela indígena en un contexto urbano", Revista de Investigación Educativa de la REDIECH vol. 4, n. ${ }^{\circ} 6$ (2013).

11 Silvia Citro, Yanina Mennelli y Soledad Torres, “'Cantando al patrimonio...: las expresiones indígenas, entre discursos globales y creatividades locales", Antípoda. Revista de Antropología y Arqueología n. ${ }^{\circ} 29$ (2017), 1.

12 María Isabel Arias y Alexander Ortiz, Currículo decolonial. Prácticas curriculares y colonialidad de la educación (Santa Marta: Editorial Unimagdalena, 2019). 
y la multivocalidad"13, este no era el caso de los adolescentes de la comunidad, quienes en el campo del arte se mostraban deseosos de las expresiones artísticas foráneas - como denominan los ancianos de la comunidad al arte extranjero-, y reacios a sus propias prácticas artísticas. Parte del problema se aprecia en el siguiente extracto de entrevista a uno de los mayores de la comunidad.

Los jóvenes de ahora no les gusta la música de sus mayores, ellos ahora les gusta las músicas foráneas, entonces ellos no les gusta lo propio. Pero debería ser al contrario, querer lo propio. La música para el Misak es pa' estar en armonía, por eso la música se aprende es por los sueños, porque uno se armoniza cuando duerme. En la noche, la madre tierra conecta espiritus naturales con el alma de la persona. ${ }^{14}$

Es así como "los saberes y tradiciones ancestrales que caracteriza la cultura propia"15 parecían contraponerse a las propuestas artísticas y culturales de tipo comercial-occidental, que se ciernen cada vez con mayor fuerza dentro de las comunidades indígenas. Con el objetivo de atenuar esta clase de divisiones entre perspectivas artísticas o sentimientos de distanciamiento por los saberes artísticos de la cultura propia o ancestral, se desarrolló el presente proyecto durante parte del año 2017 y a lo largo del año 2018. La propuesta tuvo por objetivo principal generar un fortalecimiento de las prácticas artísticas tradicionales del pueblo Misak y la pregunta generadora de la investigación fue: ¿Cómo fortalecer las prácticas artísticas tradicionales, en los escolares de los grados segundo y tercero de la Institución Educativa la Campana, perteneciente al resguardo indígena de Guambía?

Es necesario decir que el cabildo ha intentado promover "la alimentación, el conocimiento propio, el idioma, el vestido, el arte, el idioma, las prácticas culturales y agrícolas"16, entre otra formas de fortalecimiento de las diversas actividades culturales que se denominan como propias; en lo referente a la identidad social y cultural Misak, las tendencias artísticas del mercado han generado una intervención quizás invisible sobre las prácticas artísticas del sector, fortaleciendo de forma vehemente el arte foráneo, en una equivalencia de disminución por la tradición Misak.

Lo anterior es contrario a generarse un "proceso de aculturación [hacia una] forma de vida campesina"17 y se genera una aculturación hacia gustos y búsquedas artísticas urbanas, lo cual se evidenciaba con mucha fuerza en la niñez

13 Sandra Camelo, "Poéticas indígenas de resistencia y reconstrucción plural de comunidad", Nómadas n. ${ }^{\circ} 46$ (2017): 121.

14 Entrevista a Tombé, Gerardo.

15 Mauricio Sierra, "Saberes y cosmovisión del pueblo Misak en relación con el conocimiento científico escolar mediado por un diálogo de saberes en el aula” (tesis de licenciatura en educación básica con énfasis en ciencias naturales y educación ambiental, Universidad del Valle, 2014), 18.

16 Floro Alberto Tunubalá Ussa, "Saberes y tradiciones del pueblo Misak en relación con el conocimiento científico escolar: las plantas" (tesis de licenciatura en educación básica con énfasis en ciencias naturales y educación ambiental, Universidad del Valle, 2014), 13.

17 Ronald A. Schwarz, La gente de Guambía. Continuidad y cambio entre los Misak de Colombia (Popayán: Editorial Universidad del Cauca, 2018), 8. 
y la adolescencia del sector. Es necesario decir que, aunque el movimiento indígena cuenta en la actualidad con una universidad propia, Universidad Misak, se espera que dicha universidad logre generar procesos de integración artística ocupándose de este campo del saber desde las pretensiones de la interculturalidad. Si bien el centro universitario es nuevo en lo que respecta a los procesos de consolidación de la universidad colombiana - conocida desde los tiempos de la "reforma de Santander en $1826^{\prime \prime 18}$ hasta la actualidad - , a través del presente estudio se pretendió fortalecer los procesos identitarios "a través del sonido"19, o del arte en general, de tal forma que se lograse pensar en cómo dimensionar el arte propio en relación con el arte que es ofertado a la población indígena, a través de los medios de comunicación. Se pretendió entonces generar un fortalecimiento de la cultura y también, de forma indirecta, de la lengua tradicional.

En cuanto a la población, algunos escolares habían logrado un fortalecimiento de la lengua tradicional; ello se evidencia en tanto que el $40 \%$ de los estudiantes hablan el idioma castellano gracias al contacto con la sociedad occidental, "mientras que el $60 \%$ hablan el namtrik" ${ }^{20}$ como parte del saber heredado de sus progenitores (o tradición oral). Aunque el namtrik denomina varias lenguas indígenas, la lengua que se usó para el presente estudio fue el idioma ancestral, namui wam ${ }^{21}$. Es así como - en cuanto atañe al arte-, se pretendió dar lugar a las denominadas "acciones afirmativas, las políticas educativas se caracterizan por su carácter temporal, [y] por estar enfocadas exclusivamente a las poblaciones indígenas ${ }^{\prime 22}$, pero, en este caso, por una educación a través del arte. En la mayoría de los casos, los procesos de acercamiento al arte desarrollados en la escuela colombiana son escasos o no existen, situación que resulta similar en el campo de lo educativo en el mundo indígena. En este mismo orden de ideas, las propuestas didácticas suelen tener solamente el punto de vista occidental, y en directa relación con la denominada escuela tradicional nacida de la "pedagogía tradicional" 23 , escuela a la cual le resulta complejo universalizar aquello que se llama educación para así vincular al mundo indígena y su educación en ella. Con el ánimo de transformar dicha realidad se genera un estudio desde la denominada investigación-acción ${ }^{24}$, que permita otorgar al maestro la posibilidad de

18 Diana E. Soto, "Aproximación histórica a la universidad colombiana", Revista Historia de la Educación Latinoamericana, vol. 7 (2005): 110 .

19 Jaime Hormigos, "La creación de identidades culturales a través del sonido", Comunicar. Revista Científica de Educomunicación, vol. XVII, n. ${ }^{3} 34$ (2010): 91.

20 José Tumiñá y Clementina Ullune, "El fomento de la música y la danza Misak con los estudiantes de primer grado del Centro Educativo La Campana, Territorio Ancestral Misak" (tesis de pregrado en Universidad del Cauca, 2017), 47.

21 Puntualmente en esta lengua (que traducida quiere decir lengua propia), está creada la canción "El piojo", compuesta en el aula de clase como parte de la presente investigación.

22 Edwin Cruz, "La interculturalidad en las políticas de educación intercultural", Praxis \& Saber vol. 6, n. ${ }^{\circ} 12$ (2015): 204.

23 Armando Zambrano, "Pedagogía y didáctica: esbozo de las diferencias, tensiones y relaciones de dos campos", Praxis \& Saber, vol. 7, n. ${ }^{\circ} 13$ (2016): 54

24 Ana Colmenares y Lourdes Piñero, "La investigación acción. Una herramienta metodológica heurística para la comprensión y transformación de realidades y prácticas socioeducativas”, Laurus, vol. 14, n. 27 (2008): 104. 
una experiencia formativa ${ }^{25}$, pedagógico social ${ }^{26}$, como también de propiciar una innovación en lo referente a los modelos didácticos desarrollados en el campo de la Educación Artística. Es así como se dimensionó que el

[...] pedagogo es un teórico y un diseñador de juegos orientados al desarrollo de la inteligencia y, específicamente a la representación del mundo para mejoramiento de la capacidad adaptativa del ser humano.

[...]

El pedagogo pasa de ser un enseñante a un diseñador y ejecutor de criterios de acción orientados a garantizar el logro de metas o ideales, en concordancia con el tiempo y los recursos disponibles ${ }^{27}$.

Los procesos desarrollados en el campo de la educación artística en la primera infancia suelen estar direccionados - de manera desafortunada - , a la "asignatura de manualidades" 28 , mientras que la disciplina de la música suele estar al margen de dichos procesos, por cuanto suele ser poco practicada en muchas escuelas a falta de implementación, o de maestros especializados en tal ejercicio artístico. Lo expuesto se pensó en un sentido propositivo, y en el marco de este estudio, se diseñó un grupo de actividades pedagógico-musicales de alusión directa a la cultura tradicional Misak, partiendo de la propuesta teórica y epistémica de las denominadas "pedagogías decoloniales" 29 , en las cuales se busca "pensar lo decolonial pedagógicamente y lo pedagógico decolonialmente..."30, entendiendo que no se trata del arte como un pasatiempo, sino que se trata de mucho más que una obra artística. "Son herramientas pedagógicas que dan presencia a la persistencia, insistencia y pervivencia de lo decolonial, a la vez que lo construye, representa y promueve pedagógicamente" ${ }^{\prime \prime 3}$; a través del ejercicio artístico resultaba posible vincular al mismo tiempo: tradición ${ }^{32}$, pedagogía y currículo escolar ${ }^{33}$, didáctica musical, escuela y emoción, para así: "alcanzar la formación integral de las personas, que es uno de los principales objetivos

25 María del Pilar Unda y Alba Nelly Gutiérrez, "Viajes y encuentros pedagógicos como experiencias de formación de maestros", Nodos \& Nudos, vol. 4, n. ${ }^{\circ} 39$ (2015): 9.

26 Lilia Cañón, Myriam Monroy y Javier Salcedo, "Experiencia pedagógica y voz multicultural: Pasos y palabras en historia de vida de maestra afrodescendiente", Revista Historia de la Educación Latinoamericana, vol. 18, n. 27 (2016).

27 Luis Maldonado, Virtualidad y Autonomía. Pedagogía para la Equidad (Bogotá: ICONK Editorial, 2012), $27,43$.

28 Pedro Salido-López y Francisco Maeso-Rubio, "Didáctica de las enseñanzas artísticas impartidas en las Facultades de Educación y Tecnologías de la Información y la Comunicación: la webquest como estrategia metodológica construccionista”, Arte, Individuo y Sociedad, vol. 26, n. ${ }^{\circ} 1$ (2014): 159.

29 Alexander Ortiz y María Isabel Arias, "Altersofía y hacer decolonial: epistemología 'otra’ y formas 'otras' de conocer y amar", Utopía y Praxis Latinoamericana, vol. 24, n. ${ }^{\circ} 85$ (2019).

30 Alexander Ortiz, María Isabel Arias y Zaira Pedrozo, Decolonialidad de la educación. Emergencia/Urgencia de una pedagogía decolonial (Santa Marta: Editorial Unimagdalena, 2018).

31 Catherine Walsh, "Introducción. Lo pedagógico y lo decolonial. Entretejiendo caminos", en Pedagogías decoloniales. Prácticas insurgentes de resistir, (re)existir y (re)vivir, tomo 1, ed. Catherine Walsh (Quito: Abya-Yala, 2013), 23-68.

32 Schwarz, La gente de Guambía.

33 Alexander Ortiz, Decolonizar la Educación. Pedagogía, currículo y didáctica decoloniales (República de Moldavia: Editorial Académica Española, 2017). 
de la educación" ${ }^{\prime 34}$, entendiendo el vínculo entre educación y cultura como un elemento constitutivo de la formación del ser indígena.

\section{Marco teórico}

En el presente estudio se tuvo presente, desde un principio, que los problemas de aculturación se encuentran ligados al tema de identidad; por consiguiente, se dio una mirada a la relación entre cultura e identidad, las dos transversalizadas por el arte ${ }^{35}$, dando un lugar a las prácticas dancísticas y musicales como elemento constitutivo de la "formación de su identidad"36. En este mismo sentido - sin llegar a condenar o dejar a un lado las prácticas foráneas al contexto Misak-, se buscaría desarrollar un grupo de prácticas artísticas con la intensión intrínseca de fortalecer la identidad. Aunque existen múltiples investigaciones acerca del fenómeno de la identidad y su relación con la música, escasamente se encuentran investigaciones en el campo de la didáctica propiamente dicha, en donde se aborde la identidad artística como parte de un "reconocimiento identitario [...] Ello no supone abandonar los derechos culturales de los pueblos indígenas, pero sí mirarlos en un sentido más contemporáneo, que está rodeado de un desarrollo translocal, transgeneracional y pleno de mezclas" ${ }^{\prime 37}$.

Si bien resulta cierto que el arte es por naturaleza algo universal o universalizable, lo anterior no excluye pensar que el arte es susceptible de usarse para el fortalecimiento de los procesos identitarios generados en los diversos contextos, dado que "La música construye nuestro sentido de la identidad mediante las experiencias directas [...] experiencias que nos permiten situarnos en relatos culturales imaginativos" ${ }^{\prime 38}$. Avanzando sobre el tema, dentro del marco de la identidad, en los últimos años ha venido tomando mucha fuerza en Latinoamérica la propuesta de las denominadas pedagogías decoloniales, dado que a través de este enfoque se plantea una serie de "rupturas, transgresiones, desplazamientos e inversiones de los conceptos y prácticas impuestas y heredadas" ${ }^{39}$ de una sociedad occidentalizada, colonialista al tiempo que excluyente, en donde se entendía que los Estados republicanos, al ser fundados por criollos, privilegiaban los derechos de los criollos. Es así como las denominadas pedagogías decoloniales han ayudado en buena medida a formular nuevos modelos educativos propios e insurgentes, y desarrollados desde las minorías étnicas.

34 Rafael Buitrago y Lucía Herrera, "Matricular las emociones en la escuela, una necesidad educativa y social”, Praxis \& Saber, vol. 4, n. 8 (2013): 100 .

35 Homi K. Bhabha, "El entre-medio de la cultura", en Cuestiones de identidad cultural, eds. Stuart Hall y Paul du Gay (Buenos Aires: Amorrortu editores, 2003), 94.

36 Ángela Ruiz, "El papel de la música en la construcción de una identidad durante la adolescencia. ¿Dime qué escuchas y te diré quién eres?”. SINERIS. Revista de musicología n. 22 (2015): 9.

37 Imanol Aguirre y Lucina Jiménez, "Diversidad cultural y educación artística", en Educación artística, cultura y ciudadanía, eds. Imanol Aguirre, Lucina Jiménez y Lucía Pimentel (Madrid: Metas Educativas, 2011), 38.

38 Simón Frith, "Música e identidad", en Cuestiones de identidad cultural, eds. Stuart Hall y Paul du Gay (Buenos Aires: Amorrortu editores, 2003), 212.

39 Walsh, Pedagogías decoloniales, 64. 
En consecuencia en la presente propuesta - más allá de presentar una crítica a las propuestas educativas coloniales-, se pretendió hacer un aporte a la institución educativa a partir del diseño de un grupo de actividades estructuradas desde una postura decolonial ${ }^{40} 41$, postura que ha sido ampliamente difundida por la señora Catherine Walsh ${ }^{43}$, y en la que se pretende que los pueblos de América Latina se piensen a sí mismos a partir de propuestas educativas propias y de cara al fututo mismo de sus propuestas educativas. La pedagogía en esencia necesita de un corpus didáctico que la ayude a ponerse de manifiesto en el aula; en otras palabras, resulta muy complejo pensar la una sin la otra, en cualquiera de sus órdenes: pedagogía y didáctica son dos caras de una misma moneda. A partir de lo anterior hay que decir que la didáctica - en el terreno de las pedagogías decoloniales - , no ha sido lo suficientemente dimensionada y, aunque sí se evidencian algunos pasos en este campo del saber en el ámbito de la educación en general ${ }^{44}$, no ocurre igual en el área de la educación artística. Si bien no puede desconocerse que el término didáctica es eminentemente europeo, que etimológicamente "procede del griego: didaktiké, didaskein [...] Todos estos términos tienen en común su relación con el verbo enseñar, instruir, exponer con claridad" 45 , en cuanto a la presente investigación sí se pretendió generar una propuesta didáctica similar en sus objetivos a la propuesta etimológica occidental, pero generada desde un modelo didáctico intercultural y de correspondencia con la cultura misma y en lo que se refiere al uso de la lengua ancestral (como se observará más adelante). En este orden de ideas, educar implica conocer para educar. En otras palabras, antes de presentar un determinado programa de formación es necesario conocer al grupo humano al cual está dirigido; por ello resulta tan valioso que dos de los investigadores del presente estudio pertenezcan a la comunidad indígena donde se desarrolló la investigación - su lengua ancestral es el namui wam-, por cuanto fue necesario pensarse a sí mismos y a su propia cultura para poder atender a los problemas de aculturación que se desarrollaban dentro de las prácticas artísticas de la propia comunidad. Con posterioridad al presente estudio surgió la necesidad de acudir al concepto de etnoeducación, dado que se trata de un tema:

que remarca una especial importancia para las comunidades y grupos indígenas porque les permite retomar sus raíces, ser protagonistas de su propia enseñanza y

$40 \quad$ Alexander Ortiz, María Isabel Arias y Zaira Pedrozo, "Hacia una pedagogía decolonial en/desde el sur global", Revista NuestrAmérica, vol. 6, n. ${ }^{\circ} 12$ (2018): 195-222.

41 Alexander Ortiz, María Isabel Arias y Zaira Pedrozo, "Pedagogía decolonial: hacia la configuración de biopraxis pedagógicas decolonizantes", Ensayos Pedagógicos, vol. 13, n. ${ }^{\circ} 2$ (2018): 201-233.

42 Alexander Ortiz, "Decolonizar la investigación en educación", Revista Praxis vol. 13, n. ${ }^{\circ} 1$ (2017). DOI: http://dx.doi. org/10.21676/23897856.2112

43 Walsh, Pedagogías decoloniales.

44 Alexander Montes y Audin Gamboa. "Miradas sobre la calidad de la educación básica en Iberoamérica: Visiones de España y Colombia”, Revista Historia de la Educación Latinoamericana, vol 20, n.o 31 (2018).

45 Joan Mallart, "Didáctica: concepto, objeto y finalidades", en Didáctica general para psicopedagogos, eds. Félix y Rajadell Núria (Madrid: UNED, 2001), 5. 
buscar, a través de sus costumbres y tradiciones, la mejor forma para que los más pequeños aprehendan el "ser indígena", respetando su lengua y su cosmovisión. ${ }^{46}$

Es así como la etnoeducación es, además, un proyecto étnico-político, la base de un modelo pedagógico pensado para fortalecer "la capacidad de decisión que tienen los grupos étnicos respecto a sus recursos culturales" ${ }^{\prime 7}$, lo cual se debe en buena medida a los avances realizados en materia de legislación nacional en el marco de la Constitución de 1991. En este orden de ideas, se presenta también el concepto de educación intercultural, la cual puede promover diálogos en términos de igualdad, no solo para la comprensión del otro (fuera del ser), sino del otro o de los otros que pueden habitar en cada ser humano, dadas las múltiples culturas que se abren campo en la mente y en el corazón de tal o cual ciudadano. Atendiendo a lo expuesto, se optó por ofrecer una propuesta intercultural en la que fuera posible la "implementación de programas de educación formal en base a culturas y lenguas locales, regionales, nacionales y extranjeras que a lo sumo aspiran un entendimiento y menos un aprendizaje intercultural" 48 , desarrollada desde la necesidad manifiesta de los mayores de la comunidad indígena y para la atención a las nuevas generaciones de jóvenes que tendrán la responsabilidad de mantener la tradición ancestral Misak.

\section{Materiales y métodos}

En los primeros momentos de la investigación se pensó en desarrollar una etnografía dado que "La etnografía es, pues, un tránsito entre sistemas diferentes, en cierto modo entre culturas diferentes" ${ }^{\prime 9}$. A lo largo de esta etapa se generó un primer acercamiento a las particularidades de la vida escolar guambiana, interactuando con los jóvenes y maestros de la institución educativa, como también con los denominados sabedores de la comunidad. Lo anterior, al tenor de las nuevas formas o sentidos de desarrollo de la investigación con comunidades otras, quienes desde el enfoque decolonia ${ }^{50}{ }^{51}$ reclaman la intervención de metodologías otras ${ }^{52}$, en donde sea posible una propuesta, no para la comunidad sino desde la comunidad. No obstante, y aunque en la etnografía resulta posible generar transformaciones en el contexto, dados los alcances que se pretendían

46 Juliana Arbeláez y Paulina Vélez, "La etnoeducación en Colombia, una mirada indígena" (tesis de grado en Derecho, Universidad EAFIT, 2008), 6.

47 Elizabeth Castillo y Axel Rojas, Educar a los otros. Estado, políticas educativas y diferencia cultural en Colombia (Popayán: Editorial Universidad del Cauca, 2005), 32.

48 Lara, Marco et al., "Estrategia didáctica para generar aprendizajes interculturales en las unidades educativas del cantón Guaranda Provincia Bolívar - Ecuador", Talentos vol. 3, n. ${ }^{\circ} 1$ (2016): 12.

49 Honorio Velasco y Ángel Díaz, La lógica de la investigación etnográfica. Un modelo de trabajo para etnógrafos de aula (Madrid: Editorial Trotta, 2006), 42.

50 Alexander Ortiz y María Isabel Arias, "Hacer decolonial: desobedecer a la metodología de investigación”, Hallazgos vol. 16, n. ${ }^{\circ} 31$ (2019): 149-168. Doi: https://doi.org/10.15332/s1794-3841.2019.0031.06.

51 Alexander Ortiz, Decolonizar las Ciencias Sociales: hacia una investigación decolonial (Editorial Académica Española, 2018).

52 Alexander Ortiz, María Isabel Arias y Zaira Pedrozo, "Metodología 'otra’ en la investigación social, humana y educativa. El hacer decolonial como proceso decolonizante", FAIA vol. 7, n. ${ }^{\circ} 30$ (2018). 
generar con la comunidad, se determinó que la metodología por desarrollar en lo extenso de la investigación sería un trabajo desde la IA (investigación-acción), ante la idea de que, a través de este modelo, se permite:

[...] la expansión del conocimiento y por la otra va dando respuestas concretas a problemáticas que se van planteando los participantes de la investigación, que a su vez se convierten en coinvestigadores que participan activamente en todo el proceso investigativo y en cada etapa o eslabón del ciclo que se origina producto de las reflexiones constantes que se propician en dicho proceso..$^{53}$

Y de igual manera:

[...] se relaciona con los problemas prácticos cotidianos experimentados por los profesores, en vez de con los "problemas teóricos" definidos por los investigadores puros en el entorno de una disciplina del saber. Puede ser desarrollada por los mismos profesores o por alguien a quien ellos se lo encarguen [...] desde el punto de vista de quienes actúan e interactúan en la situación problema. ${ }^{54}$

El proceso contó con cuatro fases: 1-. Identificación del problema a desarrollar en el aula. 2-. Creación del repertorio a desarrollar con la población infantil ${ }^{55}$. 3-. Aplicación del método en el aula de clase. 4-. Análisis cualitativo de los resultados obtenidos con posterioridad a la aplicación de las correspondientes prácticas artísticas. En este mismo orden de ideas se desarrolló una propuesta investigativa de tipo socio - científica ${ }^{56}$, y crítico social, dado que se tenía por ideal modificar parcialmente la estructura de "la interacción social [como parte de las] disciplinas crítico-sociales" ${ }^{57}$, trascendiendo así la descripción de determinadas prácticas escolares, hacia una formulación de nuevas prácticas comunitarias.

En consecuencia, el ejercicio pretendió dar lugar a la "elaboración de una estrategia didáctica Intercultural [...] como una necesidad manifiesta de modelar una intervención didáctica desde una perspectiva más plural y democrática" ${ }^{58}$. En este mismo orden de ideas - y a pesar de que en un principio se desarrolló un trabajo de etnografía-, se indicó la aplicación del método deductivo, dado que se pretendió aplicar la propuesta en un contexto, yendo de "lo general a lo particular" 59 , de tal forma que se contaba con una construcción de premisas generales a ser aplicadas en un contexto. En lo referente a las estrategias de recolección de la información, se realizó un análisis de orden cualitativo a catorce

53 Colmenares y Piñero, “La investigación acción. Una herramienta metodológica”, $18,105$.

54 John Elliot, La investigación-acción en educación (Madrid: Ediciones Morata, 2000), 5.

55 Aunque en algún momento se pensó en la posibilidad de generar un estudio desde la perspectiva de la denominada investigación creación, se descartó ante la necesidad de generar un estudio de dimensiones más amplias, asumiéndose que la metodología en específico a desarrollar sería finalmente la IA (investigación-acción).

56 Natalia García y Leonardo Fabio Martínez. "Incidencia del abordaje de una cuestión socio-científica en la alfabetización científica y tecnológica de jóvenes y adultos”. Praxis \& Saber. Vol. 6 n.o 11. (2015).

57 Carlos Eduardo Vasco, Tres estilos de trabajo en las Ciencias Sociales (Manizales: CINEP, 1990), 11-12.

58 Lara, et al., "Estrategia didáctica", 14.

59 Eva Pasek, La construcción del problema de investigación y su discurso (Cabudare: Universidad Fermín Toro, 2008), 140-141. 
diarios de campo surgidos de las actividades desarrolladas en el aula, y siete entrevistas a los sabedores de la comunidad, con el objetivo de indagar un poco más sobre la brecha generacional establecida entre los jóvenes de la comunidad y los ancianos de la misma, de tal forma que se pudiese diseñar una buena práctica social de aula en la que fuera posible "mejorar la racionalidad y la justicia" de las "prácticas sociales o educativas" ${ }^{60}$. A lo anterior se agrega que se realizó un amplio trabajo de observación participante durante las sesiones dancísticas, como es el caso de la danza de "La chucha", y se generaron diversos videos de las distintas actividades, videos que posteriormente fueron analizados por los investigadores.

\section{Resultados}

A partir del proceso investigativo - realizado a lo largo del año 2018 con la comunidad educativa -, se logró desarrollar la categoría principal del presente texto, denominada Didácticas artísticas decoloniales, como un modelo de trabajo a desarrollar con la primera infancia indígena.

\section{Didácticas artísticas decoloniales}

Se entiende por didácticas artísticas decoloniales la multiplicidad de actividades escolares que, dentro del campo de la educación artística, están direccionadas al fortalecimiento de lo tradicional. Dentro de la propuesta se acude a los contenidos de la cultura y el idioma de la comunidad, en la clara intención de generar un fortalecimiento a través de las prácticas escolares. Se planteó desde un principio la hipótesis de que, al realizar un determinado grupo de danzas y temas musicales con los niños de la comunidad y con temáticas e idioma propios, se generaría un encuentro con la cultura propia a través del arte. Dicha propuesta estaría planteada desde una transversalidad disciplinar, involucrando diversos campos de la educación artística como son la música, la danza y las artes plásticas, todas ellas en una relación directa con "sus contextos familiares, sociales y culturales" ${ }^{\prime 61}$. Como consecuencia, a partir de dichas actividades se analizó la influencia de éstas "en la institución educativa, en las prácticas de una cultura política y en los imaginarios sociales de tolerancia y convivencia enmarcados desde las identidades institucionales, regionales y nacionales"62. El trabajo de campo se desarrolló a lo largo de once meses, interrumpidos por periodos vacacionales de finales de 2017 y mitad de 2018; a lo largo de estos momentos se hizo una intervención directa con la comunidad, todo lo cual indicó posteriormente la necesidad de analizar las diversas estrategias de recolección de la información a partir del análisis de las prácticas realizadas en clase y de algunas entrevistas

60 Sara Rodríguez et al., Investigación Acción. Métodos de investigación en Educación Especial, libro digital (2011), 4. https://es.calameo. com/read/002638567bd56389bb642

61 Ministerio de Educación Nacional de Colombia, Bases Curriculares para la Educación Inicial y Prescolar (Bogotá, 2017), 49.

62 Diana Elvira Soto et al., "La enseñanza de la independencia americana en Colombia y España, 2009-2011", Revista Historia de la Educación Latinoamericana vol. 17, n. ${ }^{\circ} 25$ (2015): 209. 
hechas a los mayores de la comunidad indígena. En el ámbito bibliográfico, se indagaron temáticas alusivas a la cultura y la didáctica, pensada esta última como el campo de saber que piensa la enseñanza y el aprendizaje, vislumbrando la posibilidad de generar un "aprendizaje entre culturas diversas"63. Con posterioridad a dicha indagación se procedió a la creación o diseño, de un grupo de actividades direccionadas a fortalecer las prácticas de reconocimiento de sí en la cultura ancestral Misak, para de esa manera "promover el diálogo de saberes entre el conocimiento propio de la comunidad Misak y el conocimiento convencional en el aula" ${ }^{\prime \prime}$, ubicando al cuerpo como un campo de acción de principal importancia en las prácticas artísticas, y teniendo muy presente que este ocupa un lugar central en el proceso creativo y también educativo.

Antes de describir las actividades artísticas desarrolladas en la escuela es necesario exponer que, durante la primera fase del proceso investigativo, se realizó un trabajo de tipo etnográfico que permitió identificar algunas problemáticas relacionadas con la aculturación que trajeron como consecuencia generar "esfuerzos por preservar y promover la cultura [hacia un] reconocimiento del otro" 65 a través de la interacción y la convivencia, posibles por medio del arte. Durante las primeras visitas al plantel se buscó identificar la forma como se desarrollarían las prácticas artísticas en la escuela y fue así como se logró detectar que muchos de los estudiantes optaban por la interpretación de ritmos y aires musicales extranjeros, en imitación de hip hoperos y reguetoneros propios de una "trama urbana" 66 , con una amplia preponderancia del segundo sobre el primero ${ }^{67}$. Lo anterior era bien temido por los mayores de la comunidad, quienes decían que: "lo que ha hecho que haya desánimo hacia lo ancestral en los jóvenes ha sido la aculturación [...] los jóvenes hacen músicas foráneas y ya no quieren tocar lo propio" 68 .

Aunque los jóvenes nunca llegaron a expresar verbalmente su rechazo a la cultura propia, sí tenían con ella un relativo distanciamiento dado el reemplazo de las prácticas artísticas de la cultura propia, por prácticas artísticas modernas de tipo comercial. En dicho proceso se observaba la influencia de los mass media, entendiendo que en la actualidad ya no se entiende por mass media únicamente la radio y la televisión - como hasta hace pocos años-, sino la telefonía celular, dado que es "en el teléfono móvil [en donde] convergen la telefonía fija, la radio, el cine, la televisión y la prensa. Incluso más, pues en algunos teléfonos móviles

\footnotetext{
63 Lara et al., "Estrategia didáctica”, 16.

64 Tunubalá Ussa, “Saberes y tradiciones del pueblo Misak”, 15.

65 Hernández, "Identidad cultural o aculturación”, 23.

66 Ángela Garcés, Paula Tamayo y José Medina, “Territorialidad e identidad hip hop. Raperos en Medellín”, Anagramas. Rumbos y sentidos de la comunicación, vol. $5, \mathrm{n}^{\circ}{ }^{\circ} 10$ (2007): 130.

67 Las expresiones culturales relacionadas con el reguetón y toda la cultura que este género musical ha generado se percibieron en una de las izadas de bandera de la institución. Resultaba curioso observar que los jóvenes indígenas se vestían como hip hoperos neoyorquinos o como reguetoneros puertorriqueños, lo cual denotaba una afinidad cultural entre ellos y una cultura musical que se ha visto ampliamente favorecida por el mercado musical de principios de siglo en los países latinoamericanos.

68 Taita de la comunidad, en comunicación personal con un anciano de la comunidad.
} 
hoy se puede hablar por Skype" 69 , y también acceder a las redes sociales ${ }^{70}$. La telefonía celular es un importante medio de información y se ha configurado como el mass media más significativo e importante de la actualidad. A partir de lo expuesto, los mayores de la comunidad percibían que las expresiones artísticas de los Misak solían ser "menospreciadas por los jóvenes de ahora"71. Para los mayores, las prácticas artísticas - que los mismos mayores denominan como foráneas - iban desplazando de manera directa la cultura propia; ello se evidenciaba en la escasa vinculación intencional de los estudiantes con las manifestaciones culturales y escolares propias.

A partir del primer acercamiento de trabajo de campo con la comunidad escolar indígena se tomó la decisión de que uno de los investigadores se encargaría de manera directa de la disciplina artística de la música, y los otros dos investigadores se encargarían de atender el campo de la danza comunitaria, con los niños y niñas de la institución. La creación de las actividades implicó generar una reflexión sobre aquello que se entendía por didáctica, indicándose el desarrollo de una "práctica social viva [que conduce de manera directa a la] sistematización y las explicaciones de la práctica pedagógica"72. Finalmente, y dada la naturaleza del presente estudio, se hizo una vasta exploración sobre el área del conocimiento de la educación artística ya que esta perspectiva en el campo de la educación permite:

Adquirir valores para la vida al educar la sensibilidad y el goce de las formas de expresión de los otros. Conocer, valorar y disfrutar de las expresiones artísticas de diferentes culturas fomenta en los jóvenes el reconocimiento y el respeto de la diversidad cultural y personal. ${ }^{73}$

Se presentó entonces una propuesta de actividades desde el campo de la Didáctica de la educación artística, gracias a la puesta en diálogo de múltiples avances generados en el campo de la Educación y la Pedagogía, toda vez que se lograse desarrollar un espacio lúdico y para el aprendizaje de la cultura Misak. El ejercicio académico-artístico pretendió vincular la emoción en la escuela a través de un acto artístico, entendiendo de antemano que "no es posible separar la emoción de la cognición, al ser procesos que están interrelacionados y que son interdependientes" ${ }^{\prime 74}$, y sopesando la posibilidad de vincular la cultura con una emoción, o con un grupo de emociones, subvencionadas por una práctica artística y para el fortalecimiento de un sentir cultural. Dentro del trabajo de aula se

69 Francisco Osorio, "La evolución de los mass media", Revista Mad, n. ${ }^{\circ} 25$ (2011): 47.

70 El uso de celulares era más frecuente entre los adolescentes que entre la niñez del sector, en consecuencia, el fenómeno no afectaba de manera directa a la niñez con la cual se realizó el presente estudio. No obstante, se determinó hacer el comentario sobre los mass media actuales dado que existe una amplia comunicación entre niños y adolescentes. Lo anterior sí determina las inclinaciones artísticas de la niñez, dada la comunicación y el ejemplo dado por sus compañeros o familiares adolescentes.

71 Padre de familia, en comunicación directa, mayo de 2018.

72 Selma Garrido, "Hacia una resignificación de la didáctica -Ciencias de la Educación, Pedagogía y Didáctica. Una revisión conceptual y una síntesis provisional", Pedagogía y Saberes, vol. 1, n. ${ }^{\circ} 39$ (2013): 118.

73 Aguirre, Jiménez y Pimentel, Educación artística, 8.

74 Buitrago y Herrera, "Matricular las emociones en la escuela", 90. 
tuvo cuidado de no presentar la cultura propia como una obligación, sino que, por el contrario, generara la posibilidad de propiciar un acto lúdico dentro de la cultura Misak y la lengua namui wam. Ya en términos de las acciones puntuales a desarrollar, se presentó la posibilidad de implementar tres actividades centrales: 1. Posibilitar un encuentro entre los mayores (ancianos-músicos) de la comunidad, y la niñez adscrita al centro docente. 2. Crear e interpretar una canción infantil indígena - en idioma ancestral - destinada a fortalecer la práctica de la lengua, como es el caso de la canción "El piojo" - o la "Canción del piojo" - 3. Se realizó la práctica tradicional dancística de "La chucha", como una estrategia encaminada a generar una danza entre niños y niñas con pasos definidos, como parte de una danza o juego comunitario, con temáticas propias de la tradición ${ }^{75}$.

\section{La canción infantil indígena: "El piojo"}

La primera actividad que se realizó, con posterioridad a las entrevistas iniciales, consistió en que los investigadores se dirigieron a la escuela y determinaron que, por su falta de uso, era necesario templar algunos de los tambores de la escuela. Con la ayuda de los mayores de la comunidad se ocuparon de enseñar un grupo de células rítmicas tradicionales a los menores de la comunidad escolar. Los mayores se encargaron entonces de enseñarles a los niños a interpretar el ritmo de bambuco (o los ritmos de bambucos); dicha actividad estuvo enfocada a generar un primer acercamiento entre los niños y los mayores. La actividad fue desarrollada en horas del descanso y los menores se vieron bastante interesados en ejecutar los instrumentos musicales. Si bien no se continuó un programa de formación en lo que respecta a percusión de ritmos indígenas, dicha actividad sirvió para dejar claro que los menores no son reacios a sus prácticas musicales, sino que muy probablemente no se había realizado la gestión de generar un encuentro entre los menores y las prácticas artísticas de su cultura, acción que sí se había generado entre los menores y las propuestas artísticas populares urbanas y modernas.

Posteriormente se pretendió crear una canción en el idioma propio de la comunidad indígena; a dicha canción se le dio el nombre de "El piojo". Si bien dentro del proyecto se desarrollaron otras actividades musicales - en algunos casos con otras canciones-, para efectos del presente escrito se optará por explicar la mencionada canción, dado que fue una actividad que no solo posibilitó múltiples aprendizajes en el aula escolar, sino que también fue ampliamente aceptada por la niñez de la institución educativa. Por ser los temas inéditos y sin comercialización alguna, los escolares no conocían ninguna de las composiciones musicales presentadas.

Además, el tema musical "El piojo" no hace parte del repertorio ancestral Misak, repertorio que cuenta con temas musicales tanto para ser cantados

$75 \quad \mathrm{Al}$ margen de las actividades expuestas en el presente estudio, se emprendieron muchas otras actividades, particularmente en el campo de las prácticas dancísticas. También se realizaron juegos de relación directa con la tradición Misak, no obstante, resulta complejo explicar las múltiples actividades desarrolladas; o ampliar el campo de análisis a la propuesta a la categoría de juego tradicional, ya que dichas temáticas desbordarían las posibilidades expositivas de la presente investigación. 
como también instrumentales como el caso de "La chucha", canción que narra la historia de un piojo que recorre diversas partes del cuerpo humano, hasta engordar y explotar.

Es de destacar que el hecho de interpretar temas musicales desconocidos o carentes de alguna popularidad, no fue en sí mismo un impedimento para que el repertorio fuese aceptado por los escolares; la observación se hace en tanto que, muchas veces, los docentes de la denominada educación artística y vinculados a la disciplina de la música, acuden a temas de la llamada "cultura popular"76 dado que el conocimiento del tema musical por parte de los estudiantes facilita su desarrollo en el aula de clase.

A partir de lo anterior se expone el contenido total del tema musical en namui wam, y su correspondiente traducción al español.

\section{Osem Pik}

Compositor: Jose Felipe Tumiñá

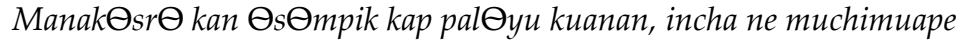

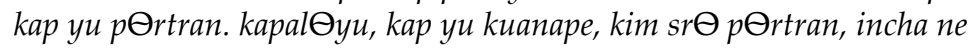

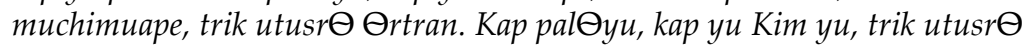

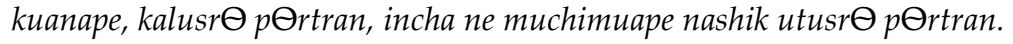

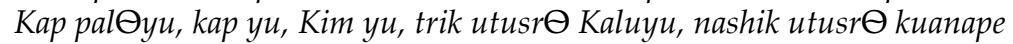

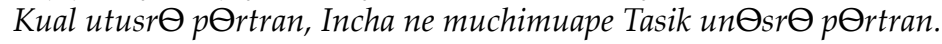

Coro: Mentra kuanape murapt $\Theta$ srutrap tintan, Mentra ani muchape pats $\Theta$ pula kuap tintan.

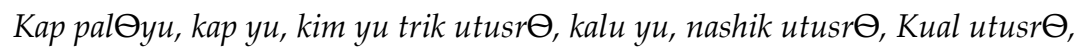

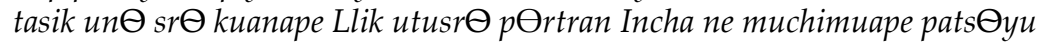

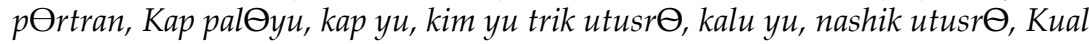

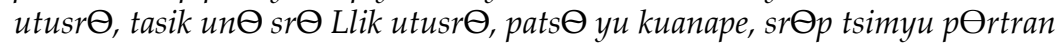

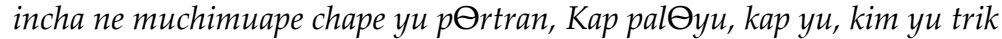
utusr $\Theta$, kalu yu, nashik utusr $\Theta$, Kual utusr $\Theta$, tasik un $\Theta$ sr $\Theta$, llik utusr $\Theta$

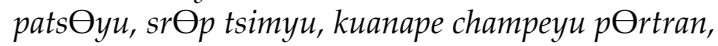

incha ne muchimuape katsik tapalyu p⿶rtran

Coro: Mentra kuanape murapt $\Theta$ srutrap tintan, Mentra ani muchape pats $\Theta$ pula kuap tintan///.

El piojo ${ }^{78}$

Una vez una pulguita en la frente picó; como le hizo falta, a los ojos saltó, en la frente y en los ojos la pulguita picó; como le hizo falta, a la nariz saltó; en la frente, en los ojos y en la nariz picó; como le hizo falta a la boca saltó.

76 Orlando Morillo, "Lo popular como expresión artística. Interculturalidad y transdisciplinariedad", Calle 14, vol. 7, n. ${ }^{\circ} 9$ (2012): 51.

77 El ejercicio de escritura en namui wam fue realizado por el compositor del tema musical, José Felipe Tumiñá. En la forma como está escrita la canción se les presentó a los estudiantes de la comunidad indígena.

78 Para efectos de la comprensión de la canción, se desarrolló un video explicativo en el cual se puede escuchar la letra del tema musical, mientras la traducción al español se encuentra expuesta en subtítulos en la parte baja del video. https://1drv.ms/v/s!Ah6B4t0AWqEUnRadoFudEMSpLtn9 
En la frente, en los ojos, en la nariz y en la boca picó; como le hizo falta, a las orejas saltó; en la frente, en los ojos, en la nariz y en la boca y a las orejas picó; como le hizo falta, hacia el cuello saltó.

En la frente, en los ojos, en la nariz y en la boca, a las orejas y al cuello picó; como le hizo falta, al brazo saltó. En la frente, en los ojos, en la nariz y en la boca, a las orejas, al cuello y al brazo picó; como le hizo falta a los dedos saltó.

Coro: De tanto picar, picar, se cansó y explotó.

Tomó mucha sangre, se engordó y explotó.

En la frente, en los ojos, en la nariz y en la boca, a las orejas, al cuello, al brazo, a los dedos picó; como le hizo falta, a la espalda pasó. En la frente, en los ojos, en la nariz y en la boca, a las orejas, al cuello, al brazo, a los dedos, a la espalda picó. Como le hizo falta, a la panza pasó.

En la frente, en los ojos, en la nariz y en la boca, a las orejas, al cuello, al brazo, a los dedos, a la espalda y a la panza picó; como le hizo falta, a los muslos pasó; en la frente, en los ojos, en la nariz y en la boca, a las orejas, al cuello, al brazo, a los dedos, a la espalda, a la panza y a los muslos picó. Como le hizo falta, a las piernas saltó.

En la frente, en los ojos, en la nariz y en la boca, a las orejas, al cuello, al brazo, a los dedos, a la espalda, a la panza, a los muslos y a las piernas picó. Como le hizo falta, a los pies saltó.

Coro: De tanto picar, picar, se cansó y explotó.

Tomó mucha sangre, se inflamó y explotó.

La canción "El piojo" tuvo como pretensión inicial ayudar a los menores de la institución a identificar las distintas partes del cuerpo humano en lengua ancestral, empezando por las partes de la cara, luego el tronco y finalmente las extremidades inferiores. La canción es en ritmo de seis por ocho (seis octavos) lo cual le da un aspecto jocoso y atractivo.

1. ${ }^{\text {ra }}$ actividad. Las prácticas de educación artística desarrolladas en la escuela guambiana tuvieron una duración de cincuenta minutos, muchas de ellas a primera hora del día. En un primer momento el docente en ejercicio e investigador $-\mathrm{y}$ además compositor del tema musical - se encargó de interpretar el tema ante sus estudiantes, de tal forma que ellos tuviesen un primer acercamiento hacia el tema musical.

2. ${ }^{\text {da }}$ actividad. Una vez interpretada la canción ante los estudiantes, el docente investigador se encargó de generar una grabación de estudio con el objetivo de tener a la mano un material de audio que pudiese ser utilizado dentro del aula de clase, con el objetivo de realizar los movimientos corporales sugeridos en la letra de la canción, al tiempo que se pudiesen dejar las manos libres de instrumentos musicales (en este caso la guitarra). Es de notar que, una vez producido dicho material de audio, la docente en ejercicio que estaba a cargo del grupo se encargó de propiciar varias audiciones de la canción durante sus jornadas de 
clase; el objetivo de las audiciones era que algunos niños, para quienes el español es su primera lengua, se familiarizaran con el tema; no todos niños manejan su lengua nativa dado que su contacto con el mundo mestizo del sector es más fuerte que el mismo contacto con su comunidad indígena.

3. ${ }^{r a}$ actividad. Dos semanas después se pasó de la audición al canto, dando comienzo a una doble interpretación del tema, una cantando y otra como parte de la "expresión y la comunicación"79, de tal suerte que dentro de la discursividad del cuerpo se encontraba expuesta la ruta que hacía el piojo, en su tránsito sobre el cuerpo humano. $\mathrm{Y}$ es de esta manera como el investigador para este momento no solo cantaba, sino que también la ejemplificaba corporalmente ante sus estudiantes.

4. ${ }^{\text {ta }}$ actividad. Alrededor de la canción se desarrollaron múltiples dinámicas, como el hecho de intentar pronunciarla en idioma español y ello en algunos momentos fue posible, aunque la métrica musical no concordara con la canción original, dado que fue compuesta originalmente en Namtrik. Dada la extensión del tema musical fue necesario también hacer el ejercicio de escritura en el cuaderno escolar, en idioma ancestral.

5. ${ }^{\text {ta }}$ actividad. Puesto que uno de los objetivos de la actividad era finalmente desarrollar una actividad académica en la que se pudiese enseñar la canción en lengua ancestral, a lo largo del proceso de investigación se realizaron actividades escriturales, lecturas de las canciones e interpretaciones de éstas; dicho proceso se desarrolló a lo largo de cinco meses de ejercicio investigativo, desarrollado durante los espacios de la asignatura de educación artística. Los investigadores encargados de la actividad determinaron, desde un principio, la necesidad de enseñar no solo una canción con letra en lengua ancestral, sino también enseñarla desde la misma lengua. Se hace esta aclaración dado que, tanto docentes como estudiantes, usan de forma cotidiana tanto el idioma español como el idioma Namtrik. Por otra parte, ya que los escolares tenían perros y gatos como mascotas no les fue difícil identificar a los piojos, además de haber conocido niños con piojos, o de haberlos sufrido ellos mismos.

$6 .^{\text {ta }}$ actividad. Finalmente, y como parte del ejercicio mismo de la expresión artística desde la tradición ancestral, se desarrolló una actividad de socialización en la cual se presentó el repertorio a los padres de familia, dándoles a conocer las vivencias artísticas desarrolladas a lo largo de este semestre.

Se logró identificar - gracias a las entrevistas con la docente y diálogos con los estudiantes-, que la asertividad de los temas musicales desarrollados se debió, en parte, al hecho de que la lengua de las canciones era, precisamente, la lengua ancestral o la denominada por el mundo occidental como "lengua materna" 80 . Por consiguiente, se asume que no hubiese resultado igualmente fácil crear e implementar las canciones en idioma español - con temáticas ances-

79 José Bolaños y Mónica Pérez, “PPor qué nos escogió a nosotros para la práctica coral, si somos tan indisciplinados?”, Nodos \& Nudos vol. 5, n. ${ }^{\circ} 42$ (2017): 96.

80 Inmaculada Santos, "Incidencia de la lectura en el vocabulario en lengua materna y extranjera", Ocnos. Revista de Estudios sobre Lectura vol. 16, n. ${ }^{\circ} 1$ (2017): 86. 
trales-, dado que para los escolares es su segunda lengua, al igual que para dos de los tres investigadores. Si bien se ha creído que la niñez aprende los contenidos gracias a un ambiente de introyección y no de movimiento, los estudios desde el campo de la psicomotricidad educativa indican lo contrario, entendida la psicomotricidad como un:

[...] conjunto de teorías y prácticas de la psicomotricidad aplicables en la escuela ordinaria [...] una forma de entender la educación, basada en la psicología evolutiva y la pedagogía activa (entre otras disciplinas), que pretende alcanzar la globalidad del niño (desarrollo equilibrado de lo motor, lo afectivo y lo mental) y facilitar sus relaciones con el mundo exterior (mundo de los objetos y mundo de los demás). ${ }^{81}$

Se partió entonces de la idea de que el niño aprende gracias a las actividades o movimientos desarrollados con su cuerpo, y de forma sensorial. La niñez indígena -en similitud con la niñez occidental u occidentalizada-, no suele sentirse gustosa del trabajo realizado en los claustros educativos; existe quizás en esta etapa de la vida un cierto espíritu aventurero que el mundo adulto, tarde o temprano, se encarga de menguar. En contravía a lo expuesto, los ambientes en los cuales se realizaron las actividades musicales (de manera aleatoria) fueron: el aula de clase, canchas de fútbol, coliseos municipales y algunas zonas verdes de la Institución Educativa La Campana.

Hacia el final del año escolar, los escolares contaban ya con algunas canciones en idioma ancestral, hecho que fue muy bien visto por los ancianos de la comunidad quienes, en tiempos precedentes, se mostraban preocupados ante la existencia de expresiones artísticas que poco o nada se relacionaban con la cultura propia. Al respecto, uno de ellos expresó: “Todo lo foráneo no es malo, porque los niños deben conocer otras culturas y explorar otros conocimientos, pero entonces que sea sin olvidar su lugar de origen".

Sobre lo anterior es de notar que, algunos docentes - tanto mestizos como Misak-, se vieron sorprendidos ante la recepción de los estudiantes indígenas para con un repertorio en lengua propia, cosa que no se esperaba pues muchos de los menores suelen verse comprometidos $-\mathrm{y}$ desde muy corta edad-, con expresiones urbanas y comerciales, como es el caso de hip hop, género que resulta normal en "los espacios públicos urbanos contemporáneos" 82 , y de repente atípico en los contextos indígenas, situación que aplica de manera similar al género del reguetón ${ }^{83}$.

Para finalizar, se aclara que en ningún momento se proscribió práctica o gusto alguno referente a música, práctica artística o indumentaria, pues el interés de los investigadores no estuvo centrado en reivindicar una cultura en contraposición a determinada propuesta comercial del mercado de la música, sino que se

81 Javier Mendiaras, "La Psicomotricidad Educativa: un enfoque natural", Revista Interuniversitaria de Formación del Profesorado vol. 22, n. ${ }^{\circ}$ (2008): 200.

82 Garcés, Tamayo y Medina, "Territorialidad e identidad", 126.

83 Priscilla Carballo, "Reggaetón e identidad masculina”, Cuadernos Intercambio sobre Centroamérica y el Caribe vol. 3, n. ${ }^{\circ} 4$ (2006): 91. 
pretendió posibilitar una convivencia entre saberes artísticos, dentro del fortalecimiento de las prácticas de lo propio, dado el tácito y previo reconocimiento de lo foráneo.

\section{Práctica dancística de "La chucha"84}

A diferencia de la canción "El piojo", que fue compuesta por uno de los investigadores para los propósitos de la presente investigación, el tema musical dancístico denominado "La chucha" es un antiguo tema ancestral que forma parte del repertorio dancístico Misak. Es posible que en otro momento de la historia dicho tema haya sido interpretado en flautas y tambores por agrupaciones de chirimía; ello hace parte de la tradición Misak y de lo que nos queda de la tradición precolombina; parte de lo dicho se argumenta en el siguiente enunciado.

Sin duda, la música, el baile, la muerte y el vestido entretejen cultura y pensamiento guambiano, buscan constantemente espacios de coexistencia y participación, y entran al campo de la transformación, la recreación y el choque. La música guambiana, las flautas y los tambores encierran un universo normativo y cognoscitivo. ${ }^{85}$

El presente estudio se dispuso como un "proyecto educativo que incluya prácticas culturales [...] y pedagógicas" ${ }^{186}$; de tal suerte que los escolares indígenas se encargarían de interpretar esta danza ancestral, generando toda una escenografía dentro de una canción en la que aparece como sujeto clave una zarigüeya (o chucha), la cual interactúa con los menores que interpretan la danza. En un ejercicio de amplificación del trabajo realizado con los escolares. A continuación, se expone la forma como se elaboró la actividad de "La chucha".

1. ${ }^{\text {ra }}$ actividad. Dentro del proyecto se desarrolló un grupo de prácticas dancísticas "cuya praxis puede ser introducida en los sistemas educativos como un eje transversal al aprendizaje y al reconocimiento del mundo" ${ }^{\prime 87}$, de tal forma que el niño relacionase la práctica dancística con aspectos de su singularidad contextual. Los ensayos de la danza de "La chucha" se realizaron en las zonas verdes de la institución educativa y dentro del tiempo de clases de educación artística. La investigadora encargada de la danza primero les enseñó a los niños y las niñas el paso básico y las respectivas diferencias en algunas partes entre las acciones de los niños y aquellas de las niñas. Este ejercicio se realizó de forma individual con cada estudiante. También se destaca que muchos de los estudiantes sugerían

84 Para efectos de la comprensión de la danza realizada con los niños y niñas de la institución, se logró generar una grabación en video sobre la socialización de la danza, la cual fue llevada a cabo en el coliseo de la ciudad de Piendamó; su elaboración contó con la ayuda de los tres investigadores. https://1drv.ms/v/s!Ah6B4t0AWqEUnRev5SYAE6TgFyPb

85 Juan Demera, "Dinámicas, configuraciones étnicas y renovaciones culturales inéditas. El caso de la más reciente evangelización protestante entre los indígenas guambianos en Colombia”, Estudios Fronterizos, vol. 6, n. ${ }^{\circ} 12$ (2005), 71.

86 Ministerio de Educación Nacional de Colombia, Bases Curriculares, 19.

87 Laura Oyuela, "La práctica dancística como una estrategia dentro del contexto educativo para el desarrollo de un cuerpo más consciente y atento", Calle 14, vol. 12, n. ${ }^{\circ} 22$ (2017): 271. 
espacios verdes y no las canchas de baloncesto de la institución, pues el césped les permitía acostarse en el piso y descansar una vez terminada la actividad.

2. ${ }^{\text {a }}$ actividad. Si bien el ritmo de "La chucha" puede ser denominado como bambuco, es necesario decir que la rítmica propiamente dicha, de seis por ocho (seis octavos), no es muy estable dentro de las melodías de la música Misak; existen aceleraciones y extensiones en el ritmo que hacen que se sienta una cierta inestabilidad en el ritmo, la cual - en opinión de los autores - , puede ser resuelta en la mente de quien escucha la interpretación del tema musical. Por esta razón no es una buena idea pasar una melodía ancestral Misak al programa Finale, un editor de partituras de origen occidental. Una vez indicada la forma como se realizaría la danza por cada uno de los integrantes, la docente encargada de esta parte de la investigación indicó a niños y niñas los respectivos pasos a desarrollar en el escenario, para así conformar los dos grandes grupos que generarían la danza.

3. ${ }^{r a}$ actividad. El tema dancístico implicó múltiples actividades académicas, en donde se transversalizaron disciplinas artísticas; si bien la música y la danza suelen estar ampliamente ligadas en la mayoría de los casos, en esta oportunidad - y además de lo ya dicho-, implicó la necesidad de dar un espacio para el arte plástico. Es así como se determinó realizar el ejercicio artístico de armar una chucha. Aunque algunos estudios dicen que "raramente atacan otros animales, como aves de corral, al encontrarlas en sus áreas de actividad" 88 , la zarigüeya (más conocida por la población indígena y campesina como chucha), ha sido históricamente acusada de perseguir y consumir gallinas de cría; como consecuencia, los pobladores (campesinos e indígenas) persiguen a las chuchas, y por esto han desaparecido o han migrado a otras zonas. La tercera actividad consistió entonces en crear una chucha con diversos materiales como cuero, icopor, paja de pasto, colbón y otros pegantes, además de algunos trozos de madera. En la elaboración se pretendió no solo que la forma de la chucha concordara con la realidad, sino también con su tamaño. Es así como, en la parte final de la danza, se encarga a uno de los niños de sacar a la chucha a pasear entre los estudiantes mientras que los demás, con la ayuda de una vara, le darían "fuete" al animal, por lo cual, hacia el final de la danza, la chucha se aleja del lugar.

4. ${ }^{\text {ta }}$ actividad. Finalmente, la práctica dancística ancestral fue socializada ante el público en el Coliseo Municipal de la ciudad de Piendamó (Cauca); con ello se presentó a padres de familia y demás ciudadanos como resultado de la actividad artística realizada a lo largo del último trimestre académico en la Institución Educativa La Campana.

Puede agregarse, para finalizar, que el pueblo Misak - como muchos otros pueblos indígenas -, posee una inherente cercanía con la naturaleza, lo cual conlleva la posible necesidad de generar temáticas ecológicas dentro de las expresiones artísticas, como es el caso de la tierra, el aire, el bosque, el páramo, el agua, las lagunas, "La pulga" y "La chucha”, entre otros. El pueblo Misak

88 Carolina Vivas, Francisco Flórez y Juan Castrillón, Pautas para el manejo de crías de zarigüeya en estado de indefensión (Medellín: Secretaría de Medio Ambiente de Medellín, 2016), 11. 
cuenta, entonces, con una amplia gama de expresiones artísticas dignas de ser sistematizadas como estrategias didácticas; ello a través de libros destinados a fortalecer el currículo escolar, guías a docentes emanadas de la comunidad misma, artículos científicos y demás formatos de divulgación del conocimiento. Existe la posibilidad de que muchas de estas expresiones artísticas del mundo indígena se pierdan con el tiempo, al no verse ancladas a un programa de enseñanza o formación escolar, en relación directa con la "tradición cultural" 89 . Por lo anterior, resulta pertinente generar campos de acción - quizás desde los estudios decoloniales-, en donde se logre "mostrar y despejar procesos, diálogos y prácticas insurgentes hacia el (re)existir y (re)vivir" ${ }^{\prime 90}$ de los pueblos aborígenes y sus artes, por cuanto se destaca también la necesidad de pensar no solo el qué enseñar en la práctica artística del ser indígena, sino también el cómo de las didácticas posibles consigo mismo y con "los otros".

\section{CONCLUSIONES}

La cuestión en torno a la educación artística como campo de acción dentro de la educación indígena requiere ejercicios como: (1) crear el qué (2) recrear lo que ha sido (3) pensar el cómo y (4) sistematizar el saber didáctico. Si bien existen posibilidades ilimitadas en lo que a fortalecimiento de la cultura se refiere, se asume que cada cultura desarrollará sus propios modelos de permanecer, dada la amplitud de posibilidades del arte "en el proceso educativo"91, o del arte "como actividad social" 92 .

La problemática permanente sobre la pérdida de la tradición por parte del mundo indígena hizo que el equipo investigador, encargado del presente estudio, pensara en la posibilidad de crear una canción infantil en lengua ancestral, como también el recrear una práctica dancística, "La chucha", todo con el objeto de generar un despliegue de la didáctica a partir de una propuesta intercultural. Los Misak - lo demuestra su historia de constantes luchas -, son culturalmente muy fuertes y han sabido mantener su cultura. Las luchas, particularmente las generadas en los años setenta, han dado grandes resultados; ello se evidencia en sus trabajos comunitarios, las mingas y las instituciones que han logrado generar, todo lo cual da cuenta de sus logros. Como consecuencia de lo anterior se cree que se deberían generar construcciones similares, ya sea en el campo del arte o de la educación artística, y de relación con el pensamiento decolonial. Por ello el presente estudio indica la necesidad de generar nuevos estudios sobre el denominado arte comunitario, como aquello que "apunta al bienestar de las personas, las ayuda a compartir experiencias y comprenderse

\footnotetext{
89 Mario Ramírez, "El tiempo de la tradición", Relaciones. Estudios de historia y sociedad vol. XXI, n. 81 (2000): 182

90 Walsh, Pedagogías decoloniales, 67.

91 Lourdes Palacios, "El valor del arte en el proceso educativo", Reencuentro n. 46 (2006): 1.

92 Jaime Cerón, “El arte como investigación”, Praxis \& Saber vol. 3, n. ${ }^{\circ} 6$ (2012): 232.
} 
entre sí. Se focaliza en grupos específicos, en sus necesidades y preferencias"93. Pensar la interculturalidad ${ }^{94}$ como una manera de hacer en la escuela - al igual que las propuestas generadas desde las denominadas epistemologías del sur-, es algo que resulta clave en el campo del arte. Sin condenar los géneros urbanos mencionados (hip hop y reguetón), en favor de determinado arte tradicional, sí resulta necesario democratizar el arte, pues las dos propuestas merecen convivir sin que ninguna desplace a la otra; dicho en otras palabras, el arte debe dirigirse hacia la coexistencia de las epistemes, como una vindicación de la interculturalidad, en donde se dimensione desde el arte, la convivencia y la paz ${ }^{95}$. No como un ideal, sino como una práctica de aula.

El presente texto se presenta entonces como una propuesta de trabajo dentro del campo de los estudios decoloniales, discursos muy fuertes en el campo ideológico, pero de los cuales aún falta mucho por construir en el campo de la educación artística. Lo anterior hace surgir nuevas preguntas: ¿Es acaso conveniente aplicar dentro de los contextos ancestrales términos como didáctica, educabilidad y educación artística? ¿O acaso dichos términos son igualmente coloniales y harían parte de una colonialidad del ser?

Si la respuesta fuera negativa, entonces la terminología usada en el marco del presente texto es solo accesoria y sirve para abrir un debate en el campo de la educación artística; se necesitaría entonces renombrar y dar forma a los modelos educativos propios. Si la respuesta fuera afirmativa, entonces se partiría de lo formulado para resignificar el arte en los pueblos no occidentales/occidentalizados. No está de más decir que, con el presente texto, se espera haber dado algunos pasos en lo referente a los campos del arte y de la educación artística, por cuanto ahora es deber de cada disciplina dar cuenta de sus propios cuestionamientos, renombramientos y resignificaciones dentro del campo de la propuesta decolonial del saber. Nunca es tarde para hacer lo necesario.

\section{REFERENCIAS}

Aguirre, Imanol y Lucina Jiménez. “Diversidad cultural y educación artística”. En Educación artística, cultura y ciudadanía, editado por Imanol Aguirre, Lucina Jiménez y Lucía Pimentel. Madrid: Metas Educativas, 2011.

Arbeláez, Juliana y Paulina Vélez. “La etnoeducación en Colombia, una mirada indígena”. Tesis de grado en Derecho, Universidad EAFIT, 2000.

Arias, María Isabel y Alexander Ortiz. Currículo decolonial. Prácticas curriculares y colonialidad de la educación. Santa Marta: Editorial Unimagdalena, 2019.

Bhabha, Homi K. "El entre-medio de la cultura". En Cuestiones de identidad cultural, editado por Stuart Hall y Paul du Gay. Buenos Aires: Amorrortu editores, 2003.

93 Mariana Nardone, “¿Qué es el arte comunitario? Definiciones de la literatura especializada iberoamericana y local”, La Plata: UNPLFaHCE, 2010. http://www.memoria.fahce.unlp.edu.ar/trab_eventos/ev.5728/ev.5728.pdf., 1.

94 Catherine Walsh, La interculturalidad en la educación (Lima: Ministerio de Educación / Unicef, 2005), 71.

95 Isabel Hernández, José Luna y Martha Cadena, “Cultura de paz: una construcción desde la educación”, Revista Historia de la Educación Latinoamericana vol. 19, n. ${ }^{\circ} 28$ (2017). 
Bolaños, José y Mónica Pérez. “¿Por qué nos escogió a nosotros para la práctica coral, si somos tan indisciplinados?". Nodos $\mathcal{E}$ Nudos 5, n. ${ }^{\circ} 42$ (2017).

Buitrago, Rafael y Lucía Herrera "Matricular las emociones en la escuela, una necesidad educativa y social". Praxis $\mathcal{E}$ Saber 4 , n. ${ }^{\circ} 8$ (2013): 87-100.

Camelo, Sandra. "Poéticas indígenas de resistencia y reconstrucción plural de comunidad". Nómadas n. ${ }^{\circ} 6$ (2017): 111-127.

Cañón, Lilia, Myriam Monroy y Javier Salcedo. “Experiencia pedagógica y voz multicultural: Pasos y palabras en historia de vida de maestra afrodescendiente". Revista Historia de la Educación Latinoamericana 18, n. 27 (2016): 167-190.

Carballo, Priscila. "Reggaetón e identidad masculina". Cuadernos Intercambio sobre Centroamérica y el Caribe 3, n. ${ }^{\circ} 4$ (2006): 87-101.

Castillo, Elizabeth y Axel Rojas. Educar a los otros. Estado, politicas educativas y diferencia cultural en Colombia. Popayán: Editorial Universidad del Cauca, 2005.

Cerón, Jaime. “El arte como investigación”. Praxis \& Saber 3, n. 6 (2012): 231-238.

Citro, Silvia, Yanina Mennelli y Soledad Torres. "'Cantando al patrimonio...': las expresiones indígenas, entre discursos globales y creatividades locales". Antípoda. Revista de Antropología y Arqueología n. ${ }^{\circ} 29$ (2007): 175-197.

Colmenares, Ana y María Lourdes Piñero. “La investigación-acción. Una herramienta metodológica heurística para la comprensión y transformación de realidades y prácticas socioeducativas". Laurus 14, n. ${ }^{\circ} 27$ (2008): 96-114.

Cruz, Edwin. "La interculturalidad en las políticas de educación intercultural”. Praxis \& Saber 6, n. ${ }^{\circ}$ 12 (2015): 191-205.

Chiappe, Carlos. “¿Transculturación o acultura? Matices conceptuales en Juan van Kessel y Alejandro Lipschutz". Revista de Ciencias Sociales n. 35 (2015): 47-57.

Demera, Juan. "Dinámicas, configuraciones étnicas y renovaciones culturales inéditas. El caso de la más reciente evangelización protestante entre los indígenas guambianos en Colombia". Estudios Fronterizos 6, n. ${ }^{\circ} 12$ (2005).

Elliot, John. La investigación-acción en educación. Madrid: Ediciones Morata, 2000.

Frith, Simón. "Música e identidad". En Cuestiones de identidad cultural, editado por Stuart Hall y Paul du Gay. Buenos Aires: Amorrortu Editores, 2003.

Garcés, Ángela, Paula Tamayo y José Medina. “Territorialidad e identidad hip hop. Raperos en Medellín". Anagramas. Rumbos y sentidos de la comunicación 5, n. ${ }^{\circ} 10$ (2007).

García, Natalia, y Leonardo Martínez Pérez. "Incidencia del abordaje de una cuestión socio-científica en la alfabetización científica y tecnológica de jóvenes y adultos". Praxis \& Saber. n. ${ }^{\circ}$ 6(11), 87 - 114. (2015). https://doi.org/10.19053/22160159.3576

Garrido, Selma. “Hacia una resignificación de la didáctica - Ciencias de la Educación, Pedagogía y Didáctica - . Una revisión conceptual y una síntesis provisional". Pedagogía y Saberes 1, n. ${ }^{\circ}$ 39 (2013).

Hernández, Isabel, José Luna y Martha Cadena. “Cultura de paz: una construcción desde la educación". Revista Historia de la Educación Latinoamericana 19, n. ${ }^{\circ} 28$ (2017): 149-172.

Hernández, Ramón. "Identidad cultural o aculturación: el dilema de una escuela indígena en un contexto urbano". Revista de Investigación Educativa de la REDIECH 4, n. ${ }^{\circ} 6$ (2013): 19-24.

Hormigos, Jaime "La creación de identidades culturales a través del sonido". Comunicar. Revista Científica de Educomunicación XVII, n. ${ }^{\circ} 34$ (2010): 91-98.

Lara, Marco, Marco Paredes, María Pazmiño, Henry Albán, Carlos Balda, Cecilia Venegas, Rafael Medina y Fidel Castro. "Estrategia didáctica para generar aprendizajes interculturales en las unidades educativas del cantón Guaranda". Talentos 3, n. ${ }^{\circ} 1$ (2016).

Maldonado, Luis. Virtualidad y Autonomía. Pedagogía para la Equidad. Bogotá: ICONK Editorial, 2012.

Mallart, Joan. “Didáctica: concepto, objeto y finalidades". En Didáctica general para psicopedagogos, editado por Félix y Rajadell Núria. Madrid: UNED, 2001.

Mendiaras, Javier. "La Psicomotricidad Educativa: un enfoque natural”. Revista Interuniversitaria de Formación del Profesorado 22, n. ${ }^{\circ} 2$ (2008): 199-220.

Ministerio de Educación Nacional de Colombia. Bases Curriculares para la Educación Inicial y Prescolar. Bogotá, 2017. 
Montes, Alexander y Audin Gamboa. "Miradas sobre la calidad de la educación básica en Iberoamérica: Visiones de España y Colombia". Revista Historia de la Educación Latinoamericana 20, n. ${ }^{\circ}$ 31 (2018).

Morillo, Orlando. "Lo popular como expresión artística. Interculturalidad y transdisciplinariedad". Calle 14 7, n. ${ }^{\circ} 9$ (2012): 44-55.

Nardone, Mariana. ¿Qué es el arte comunitario? Definiciones de la literatura especializada iberoamericana y local. La Plata: UNPL-FaHCE, 2010. http://www.memoria.fahce.unlp. edu.ar/trab_eventos/ev.5728/ev.5728.pdf., 1

Ortiz, Alexander "Decolonizar la investigación en educación". Revista Praxis 13, n. 1 (2017). DOI: http://dx.doi.org/10.21676/23897856.2112

Ortiz, Alexander "Decolonizar las Ciencias Sociales: hacia una investigación decolonial”. Editorial Académica Española, 2018.

Ortiz, Alexander y María Isabel Arias. "Altersofía y hacer decolonial: epistemología 'otra' y formas 'otras' de conocer y amar". Utopía y Praxis Latinoamericana 24, n. 85 (2019): 89-116.

Ortiz, Alexander y María Isabel Arias. "Hacer decolonial: desobedecer a la metodología de investigación". Hallazgos 16, n. ${ }^{\circ} 31$ (2019): 149-168. Doi: https://doi.org/10.15332/s17943841.2019.0031.06. ISSN: 1794-3841. e-ISSN: 2422-409X. https://revistas.usantotomas.edu. co/index.php/hallazgos/issue/view/472

Ortiz, Alexander, María Isabel Arias y Zaira Pedrozo. "Hacia una pedagogía decolonial en/desde el sur global". Revista NuestrAmérica 6, n. ${ }^{\circ} 12$ (2018): 195-222. www.revistanuestramerica. cl; contacto@revistanuestramerica.cl. Concepción, Chile

Ortiz, Alexander, María Isabel Arias y Zaira Pedrozo. “Metodología 'otra' en la investigación social, humana y educativa. El hacer decolonial como proceso decolonizante". FAIA 7, n. ${ }^{\circ}$ 30 (2018): 172-200.

Ortiz, Alexander, María Isabel Arias y Zaira Pedrozo. "Pedagogía decolonial: hacia la configuración de biopraxis pedagógicas decolonizantes". Ensayos Pedagógicos 13, n. 2 (2018): 201-233. DOI: https://doi.org/10.15359/rep.13-2.10. (http://www.revistas.una.ac.cr/index.php/ ensayospedagogicos/index)

Ortiz, Alexander, María Isabel Arias y Zaira Pedrozo. Decolonialidad de la educación. Emergencial Urgencia de una pedagogía decolonial. Santa Marta: Editorial Unimagdalena, 2018.

Ortiz, Alexander. Decolonizar la Educación. Pedagogía, currículo y didáctica decoloniales. Editorial Académica Española, 2018.

Osorio, Francisco. "La evolución de los mass media”. Revista Mad n. ${ }^{\circ} 5$ (2011): 43-50.

Oyuela, Laura. "La práctica dancística como una estrategia dentro del contexto educativo para el desarrollo de un cuerpo más consciente y atento". Calle 14 12, n. 22 (2017): 268-279.

Palacios, Lourdes. "El valor del arte en el proceso educativo". Reencuentro n. ${ }^{\circ} 46$ (2006).

Pasek, Eva. La construcción del problema de investigación y su discurso. Cabudare: Universidad Fermín Toro, 2008.

Pérez-Brignoli, Héctor. "Aculturación, transculturación, mestizaje: metáforas y espejos en la historiografía latinoamericana". Cuadernos de Literatura XXI, n. ${ }^{\circ} 41$ (2017).

Ramírez, Mario. "El tiempo de la tradición". Relaciones. Estudios de historia y sociedad XXI, n. ${ }^{\circ} 81$ (2000).

Rodríguez, Sara, Noelia Herráiz, Marta Prieto, Marta Martínez, Maribel Picazo, Irene Castro y Sara Bernal. Investigación Acción. Métodos de investigación en Educación Especial. Libro digital, 2011. https://es.calameo.com/read/002638567bd56389bb642

Ruiz, Ángel. “El papel de la música en la construcción de una identidad durante la adolescencia. ¿Dime qué escuchas y te diré quién eres?". SINERIS. Revista de musicología n. ${ }^{\circ} 22$ (2015).

Salido-López, Pedro y Francisco Maeso-Rubio. “Didáctica de las enseñanzas artísticas impartidas en las Facultades de Educación y Tecnologías de la Información y la Comunicación: la webquest como estrategia metodológica construccionista". Arte, Individuo y Sociedad 26, n. ${ }^{\text {. }}$ 1 (2014): 153-172.

Sámano, Miguel. "Identidad étnica y la relación de los pueblos indígenas con el Estado mexicano". Ra Ximhai 1, n. ${ }^{\circ} 2$ (2005). 
Santos, Inmaculada. "Incidencia de la lectura en el vocabulario en lengua materna y extranjera". Ocnos. Revista de Estudios sobre Lectura 16, n. ${ }^{\circ} 1$ (2017): 79-88.

Schwarz, Ronald A. La gente de Guambía. Continuidad y cambio entre los Misak de Colombia. Popayán: Editorial Universidad del Cauca, 2018.

Sierra, Mauricio. "Saberes y cosmovisión del pueblo Misak en relación con el conocimiento científico escolar mediado por un diálogo de saberes en el aula". Tesis de licenciatura en educación básica con énfasis en ciencias naturales y educación ambiental. Universidad del Valle, 2014.

Soto, Diana Elvira, Sandra Bernal, William Pacheco, Yules Espinosa, Liliana Paternina y Beatriz Perelló. "La enseñanza de la independencia americana en Colombia y España, 2009-2011". Revista Historia de la Educación Latinoamericana 17, n. 25 (2015): 187-212.

Soto, Diana Elvira. "Aproximación histórica a la universidad colombiana". Revista Historia de la Educación Latinoamericana 7 (2005): 101-138.

Tumiñá, José y Clementina Ullune. “El fomento de la música y la danza Misak con los estudiantes de primer grado del Centro Educativo La Campana, Territorio Ancestral Misak". Tesis de pregrado en Universidad del Cauca, Popayán, 2017.

Tunubalá Ussa, Floro. "Saberes y tradiciones del pueblo Misak en relación con el conocimiento científico escolar: las plantas". Tesis de licenciatura en educación básica ciencias naturales y educación ambiental, Universidad del Valle, 2014.

Unda, María del Pilar y Alba Nelly Gutiérrez. “Viajes y encuentros pedagógicos como experiencias de formación de maestros". Nodos $\mathcal{E}$ Nudos 4, n. 39 (2015).

Vasco, C. Tres estilos de trabajo en las Ciencias Sociales. Manizales: CINEP, 1990.

Velasco, Honorio y Ángel Díaz. La lógica de la investigación etnográfica. Un modelo de trabajo para etnógrafos de aula. Madrid: Editorial Trotta, 2006.

Vivas, Carolina, Francisco Flórez y Juan Castrillón. Pautas para el manejo de crías de zarigüeya en estado de indefensión. Medellín: Secretaría de Medio Ambiente de Medellín, 2016.

Walsh, Catherine. "Introducción. Lo pedagógico y lo decolonial. Entretejiendo caminos". En Pedagogías decoloniales. Prácticas insurgentes de resistir, (re)existir y (re)vivir, editado por C. Walsh. Quito: Ediciones Abya-Yala, 2013.

Walsh, Catherine. La interculturalidad en la educación. Lima: Ministerio de Educación/Unicef, 2005.

Zambrano, Armando. "Pedagogía y didáctica: esbozo de las diferencias, tensiones y relaciones de dos campos". Praxis \& Saber 7, n. ${ }^{\circ} 13$ (2016): 45-61.

Cómo citar:

Bolaños Motta, José Ignacio; Tumiñá, José Felipe; Ullune Almendra, Clementina. “Hacia una Didáctica Artística Decolonial. Una propuesta de aula intercultural desde el pueblo Misak" Revista Historia de la Educación Latinoamericana. vol. 22 No. 34 (2020): 135-159 DOI: https://doi.org/10.19053/01227238.10903

(@) $\mathbb{\Theta \Theta}$ Es Esta obra está bajo una licencia Creative Commons. Reconocimiento-No Comercial-Sin Obra Derivada 2.5 Colombia. 